Document downloaded from:

http://hdl.handle.net/10251/105557

This paper must be cited as:

Esteve-Adell, I.; Bakker, N.; Primo Arnau, AM.; Hensen, EJM.; García Gómez, H. (2017). Graphene as Metal-Free Catalyst for Aqueous Phase Reforming of Ethylene Glycol. ChemistrySelect. 2(22):6338-6343. doi:10.1002/slct.201701138

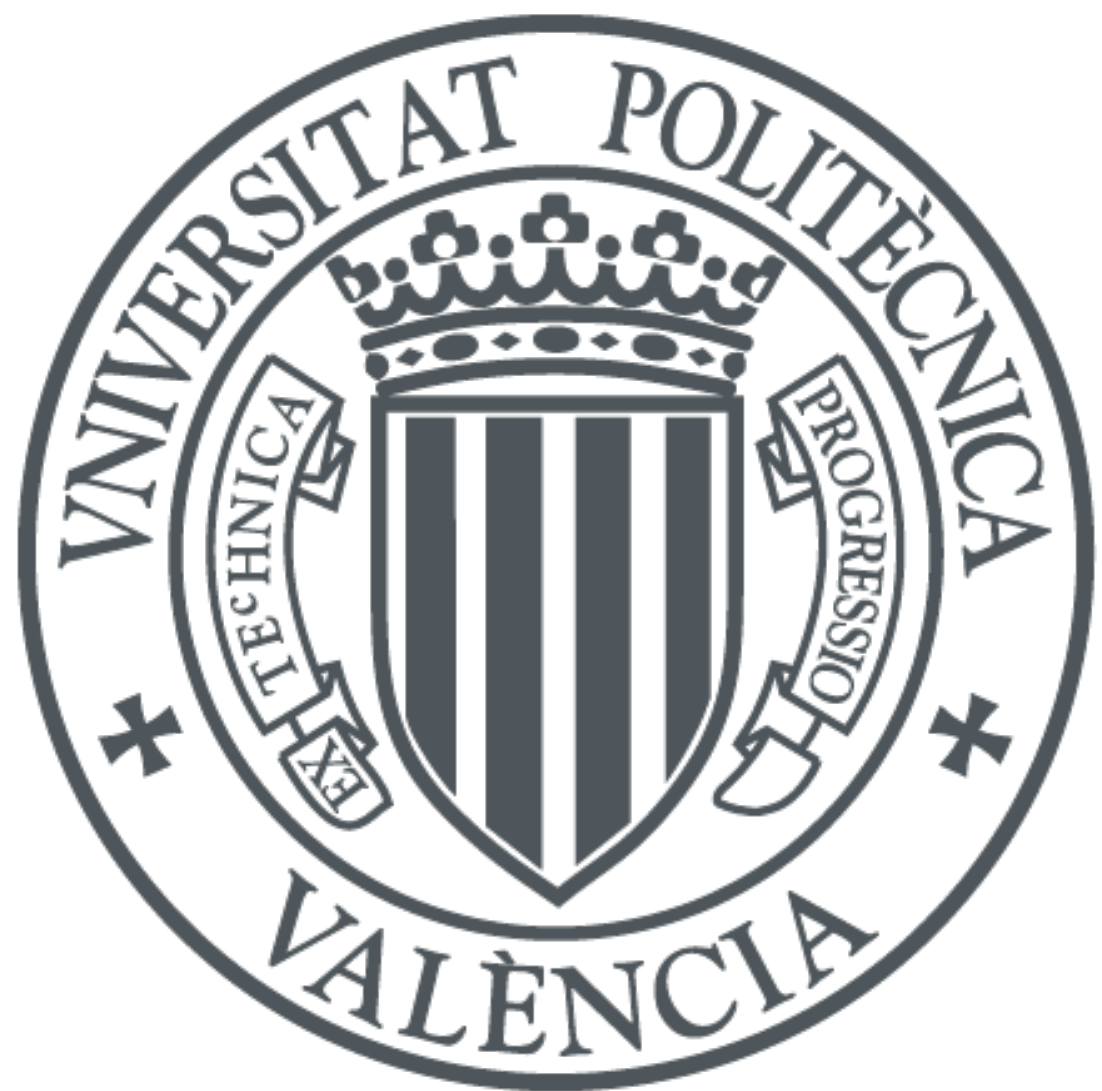

The final publication is available at

https://doi.org/10.1002/slct.201701138

Copyright John Wiley \& Sons

Additional Information 


\title{
Graphene as metal free catalyst for aqueous phase reforming of ethylene glycol
}

\author{
Iván Esteve-Adell ${ }^{a}$, Nadia Bakker ${ }^{a, b}$, Ana Primo $^{a}$, Emiel J.M. Hensen ${ }^{b}$, Hermenegildo García ${ }^{\star a}$
}

\begin{abstract}
Graphene obtained by pyrolysis of alginate shows in the absence of any metal catalytic activity towards the decomposition of ethylene glycol into hydrogen and carbon dioxide at 250 oc due to the presence of hydrogenating/dehydrogenating sites.
\end{abstract}

For the sake of sustainability there is much current interest in replacing catalysts containing noble or critical metals by other alternatives based on abundant materials ${ }^{[1]}$. When obtained from biomass, carbon-based catalysts are renewable and sustainable materials, there being and increasing research effort aimed at exploiting their use as metal-free heterogeneous catalysts. Among carbon-based materials, graphene $(G)$ and derivatives offer unique and tunable structural, chemical and physical properties that make them well suited as catalysts ${ }^{[2]}$. $G$ is a oneatom-thick carbon material with high surface area, high adsorption capacity and which is easily dispersible in liquids ${ }^{[3]}$. Size-wise, it corresponds to the physical limit of miniaturization of a surface. While ideal $G$ is considered to be devoid of active sites, the presence of defects and dopant elements can introduce catalytic centres that can promote chemical reactions ${ }^{[4]}$ Gs as carbocatalysts have already been demonstrated to catalyse carbon-centred radical oxidations of hydrocarbons, benzyl alcohols, amines and thiols among other compounds ${ }^{[5]}$. One of the challenges in carbocatalysis by Gs is to demonstrate their utility in catalysing chemical reactions that up to now require noble metals, such as hydrogenations, cross couplings and rearrangements. In the present manuscript it will be shown that defective $\mathrm{G}$ obtained by pyrolysis of alginate is a suitable carbocatalyst to promote aqueous phase reforming (APR) of ethylene glycol (EG). In the context of transformation and valorisation of biomass residues, one of the more promising possibilities is to convert aqueous waste streams, typically containing carbohydrate residue derived from cellulose and hemicellulose, into $\mathrm{H}_{2}$ by APR ${ }^{[6]}$. A common reaction to evaluate the activity of catalysts for APR is the conversion of aqueous solutions of EG. It has been found that $\mathrm{Pt}$ nanoparticles supported on large surface area metal oxides like $\mathrm{TiO}_{2}$ are among the most efficient APR catalysts of EG at around

[a] Iván Esteve-Adell, Nadia Bakker, Ana Primo, Hermenegildo García* Instituto de Tecnología Química, Universitat Politècnica de València-Consejo Superior de Investigaciones Científicas, Av. De los Naranjos s/n, 46022, Valencia, Spain.

E-mail: hgarcia@qim.upv.es

[b] Nadia Bakker, Emiel J.M. Hensen

Department of Chemical Engineering and Chemistry, Eindhoven University of Tecnology, P.O. Box 513, 5600 MB Eindhoven, The Netherlands.

Supporting information for this article is given via a link at the end of the document.
$250{ }^{\circ} \mathrm{C}^{[7]}$. Other transition metals with hydrogenating/dehydrogenating activity such as $\mathrm{Pd}$ and $\mathrm{Ni}$, although less active than $\mathrm{Pt}$, have also been reported as APR catalysts ${ }^{[8]}$. In some metal containing catalysts, a synergy has been found by combining Pt with oxophilic transition metals as Lewis acids such as for instance Re or $\mathrm{Mo}^{\left[{ }^{9]}\right.}$. However, as far as we know, no metal-free catalysts have been so far reported for this process. In the present work we report that defective $G$ derived from alginate pyrolysis catalyzes APR of EG much more efficiently than graphene oxide (GO) or reduced GO (rGO).

$G$ used as catalyst in the present study was prepared by pyrolysis at $900^{\circ} \mathrm{C}$ of alginate, followed by subsequent exfoliation. Scheme 1 illustrates the preparation procedure of defective $\mathrm{G}$ by alginate pyrolysis ${ }^{[10]}$.

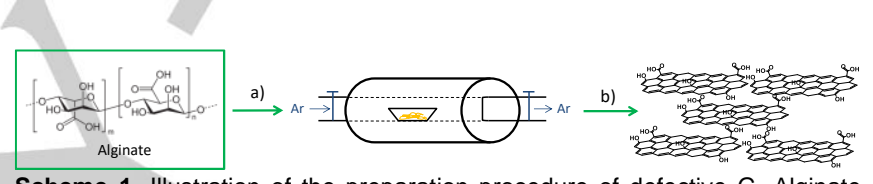

Scheme 1. Illustration of the preparation procedure of defective G. Alginate pyrolysis at $900{ }^{\circ} \mathrm{C}$ under inert atmosphere (a) followed by sonication of the resulting graphitic powder (b) to obtain dispersed $f l-G$.

For comparison purposes, this study also includes activity tests of GO obtained from graphite by Hummers-Offeman oxidation, followed by sonication ${ }^{[11]}$ and reduced graphene oxide (rGO) prepared by hydrothermal reduction of GO in autoclave at 150 ${ }^{\circ} \mathrm{C}$ for $5 \mathrm{~h}^{[12]}$. The series of materials were characterized by Raman spectroscopy and imaging techniques. As reported, Raman spectra of $G$ exhibits the $2 D, G$ and $D$ band at about $2750,1590,1350 \mathrm{~cm}^{-1}$, respectively. The relative intensity of the $G$ vs. $D$ band provides a quantitative indication that the defects density becomes larger as $I_{G} / I_{D}$ decreases. In the $G$ sample used in the present study $I_{G} / I_{D}$ amounts to 1.15 . This value for $I_{G} / I_{D}$ for the $G$ sample is similar to that of $r G O$ (1.08). The presence of the $D$ band indicates the presence of defects on the $G$ sheet, which are associated with carbon vacancies and oxygenated groups. The oxygen content of $\mathrm{G}$ estimated by XPS was about $8 \%$.

The 2D morphology and the dimensions of the $\mathrm{G}$ sheets were determined by transmission electron microscopy (TEM). Figure 1 $a$ and $b$ shows images of TEM taken for the G sample, where the lateral size was estimated to be about $3 \mu \mathrm{m}$. High resolution TEM shows the hexagonal arrangement and ordering at atomic scale, which is expected for a $\mathrm{G}$ material.

The single or few layers morphology of $G$ used as catalyst was determined by AFM. Figure $1 \mathrm{c}$ shows a frontal view of one of these sheets as well as its corresponding thickness of $2 \mathrm{~nm}$. AFM measurements show that, most of the $G$ particles have a thickness between 0.4 and $3 \mathrm{~nm}$, indicating that suspended $\mathrm{G}$ is constituted by a distribution of single and few layer Gs. 

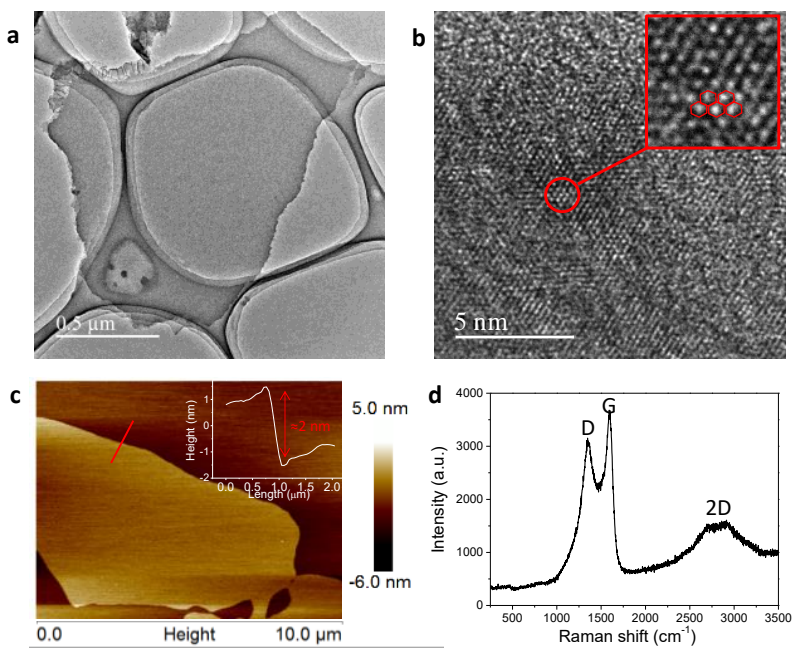

Figure 1. TEM (a) and HRTEM (b) images at two different magnifications of $G$ highlighting in red its morphology and hexagonal arrangement. Panel $c$ shows a frontal AFM view of one particle with its corresponding thickness of $2 \mathrm{~nm}$ (inset). Panel d shows the Raman spectra recorded using $514 \mathrm{~nm}$ excitation laser.

\section{Catalytic Activity for APR of EG}

As indicated in the introduction APR of EG is a test reaction commonly used to evaluate the catalytic activity of different materials for APR. Equation 1 indicates the expected stoichiometry of APR for complete mineralization of EG.

$$
\mathrm{C}_{2} \mathrm{H}_{6} \mathrm{O}_{2}+2 \mathrm{H}_{2} \mathrm{O} \rightarrow 5 \mathrm{H}_{2}+2 \mathrm{CO}_{2} \text { (eq. 1) }
$$

A preliminary blank control under the reaction conditions (autoclave $250 \stackrel{\circ}{\circ}$, 1 atm initial pressure) in the absence of any catalyst showed that uncatalyzed, spontaneous $\mathrm{H}_{2}$ generation reaches $14.1 \% \mathrm{~mol} \mathrm{H} / \mathrm{mol} \mathrm{EG}$, accompanied by $7.2 \% \mathrm{~mol}$ $\mathrm{CO}_{2} / \mathrm{mol} \mathrm{EG}$ in $3 \mathrm{~h}$, growing in percentage along the reaction time. When any of the carbocatalysts under study $(100 \mathrm{mg})$ was present in the system, an increase in the production of $\mathrm{H}_{2}$ and $\mathrm{CO}_{2}$ was observed. Besides $\mathrm{H}_{2}$ and $\mathrm{CO}_{2}$, much smaller amounts of $\mathrm{CH}_{4}\left(4.7 \%\right.$ maximum mol $\left.\mathrm{CH}_{4} / \mathrm{mol} \mathrm{EG}\right)$ together with ethane and ethylene in trace quantities were also detected. The exact temporal evolution of $\mathrm{H}_{2}$ and the amount at final reaction time was clearly dependent on the nature of the carbocatalyst as shown in Figure 2. From this Figure, it can be concluded that the activity of the samples for $\mathrm{H}_{2}$ generation follows the order $\mathrm{G}>$ $\mathrm{GO}>\mathrm{rGO}$ showing that the catalytic activity of $\mathrm{G}$ prepared from alginate is superior to that of materials derived from graphite.
The same activity order was also observed when monitoring the $\mathrm{CO}_{2}$ evolution (see inset of Figure 2 for the amount of $\mathrm{CO}_{2}$ at $3 \mathrm{~h}$ reaction time). It was observed that the amount of $\mathrm{CO}_{2}$ evolved was always higher than the value expected according to the stoichiometry presented in equation 1 . This could be due to the contribution to the $\mathrm{CO}_{2}$ formed from the catalyst or to the occurrence, at least partially, of different processes other than the desired APR, such as incomplete mineralization. To address this issue, another control experiment was carried out without $E G$ under otherwise similar conditions. It was observed that, in the absence of $E G$, self-reforming of the carbocatalyst was negligible. After $3 \mathrm{~h}$ reaction time, the amount of $\mathrm{H}_{2}$ was negligible $(0.37 \mathrm{mmol})$ and the evolution of $\mathrm{CO}_{2}(0.36 \mathrm{mmol})$ was also much lower in comparison to values observed in the presence of EG. Thus, the available data indicate that the most likely origin of $\mathrm{H}_{2}$ and $\mathrm{CO}_{2}$ when $\mathrm{EG}$ is present is the APR of this diol or that $E G$ or the products derived from it activate the decomposition of the carbocatalyst. When considering the data shown in Figure 2 it has to be reminded that the maximum amount of $\mathrm{H}_{2}$ that could be expected in the process is $500 \% \mathrm{~mol}$ $\mathrm{H}_{2} / \mathrm{mol} E G$, if the total APR of EG as indicated in the equation 1 would be the only process occurring.

Table 1 summarises under the optimal conditions the carbon mass balance and the percentage of products evolved in the gas phase and remaining in the liquid residue at final reaction time.

Table 1. Composition of the gas and the liquid phases in the APR of EG in the presence and absence of G as metal-free catalyst. Reaction conditions: temperature $250^{\circ} \mathrm{C}, 4.49 \mathrm{mmol} \mathrm{EG}, 10 \mathrm{v} / \mathrm{v} \% \mathrm{EG} / \mathrm{H}_{2} \mathrm{O}$, catalyst $110 \mathrm{mg}$.

\begin{tabular}{|c|c|c|c|c|c|c|c|c|c|c|}
\hline & \multicolumn{5}{|c|}{ Gas-phase composition (mmol) } & \multicolumn{5}{|c|}{ Liquid-phase composition (mmol) } \\
\hline Catalyst & $\mathrm{H}_{2}$ & $\mathrm{CO}_{2}$ & $\mathrm{CH}_{4}$ & $\mathrm{C}_{2} \mathrm{H}_{6}$ & $\mathrm{C}_{2} \mathrm{H}_{4}$ & EG & Methanol & Ethanol & Acetic Acid & Unidentified products \\
\hline $\mathbf{G}$ & 4.3 & 3.3 & 0.22 & 0.1 & 0.27 & 0.44 & 0.22 & 0.54 & 0.27 & - \\
\hline $\begin{array}{c}\text { C mass } \\
\text { balance (\%) }\end{array}$ & \multicolumn{5}{|c|}{47.5} & \multicolumn{4}{|c|}{30.5} & 22 \\
\hline Blank & 0.63 & 0.32 & 0.03 & - & 0.13 & 3.92 & - & - & - & - \\
\hline $\begin{array}{c}\text { Mass } \\
\text { balance }\end{array}$ & \multicolumn{5}{|c|}{6.8} & \multicolumn{4}{|c|}{87.5} & 5.5 \\
\hline
\end{tabular}

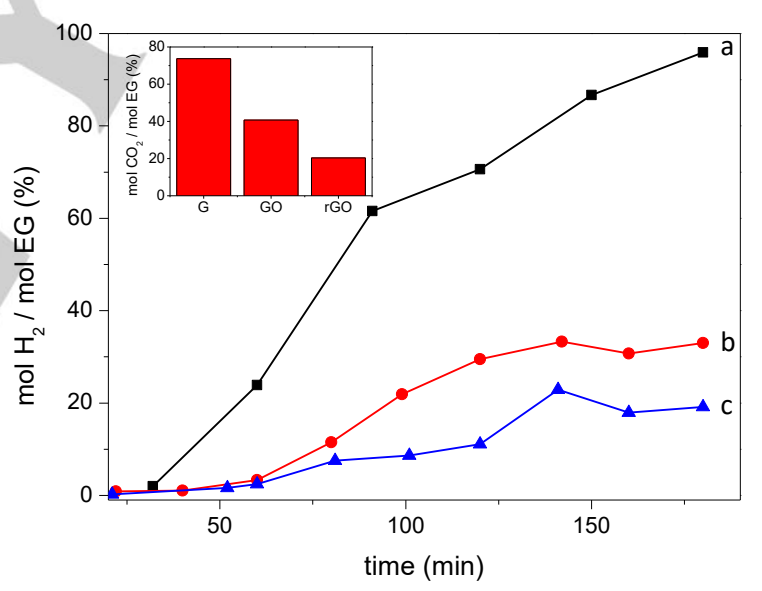

Figure 2. Temporal evolution of $\mathrm{H}_{2}$ in the APR of $E G$ in the presence of metalfree carbocatalysts. The inset shows the amount of $\mathrm{CO}_{2}$ formed in the same processes al $3 \mathrm{~h}$ reaction time. a) $\mathrm{G}$ b) GO c) rGO. Reaction conditions: $250 \stackrel{\circ}{\circ}$, $1 \mathrm{~atm}, 4.48 \mathrm{mmol} \mathrm{EG}, 10 \% \mathrm{v} / \mathrm{v} \mathrm{EG} / \mathrm{H}_{2} \mathrm{O}$. 
One point of concern when dealing with Gs as metal free catalyst is to address the role of possible metal impurities that could be present in the system. In this regard, it has to be commented that, for the samples under study, the most active $G$ catalyst was prepared by pyrolysis of alginate from algae that were never exposed to transition metals during preparation. This absence of chemical treatment with metals contrasts with the preparation procedure of GO from graphite by deep chemical oxidation, which is performed in the presence of excessive amounts of Mn. However, GO is about 3 times much less active than $G$. To gain further information on the possible influence of transition metals on the activity of $G$ and considering that in APR of EG supported metals having hydrogenating activity are common APR metal catalysts, we performed a series of experiments in which the activity of $G$ in the absence and in the presence of increasing amounts of $\mathrm{Ni}$ was compared. Considering that typical metal impurities are in percentages below $100 \mathrm{ppm}{ }^{[13]}$, besides the reaction in the absence of any added $\mathrm{Ni}$, the catalytic activity of $\mathrm{G}$ was also evaluated by purposely addition of 20,40 and $80 \mathrm{ppm}$ of $\mathrm{Ni}\left(\mathrm{NO}_{3}\right)_{2}$ relative to the amount of $\mathrm{G}$ (Figure S1). The results show that in this concentration range there is no a significant influence of the presence of $\mathrm{Ni}$ respect to $\mathrm{H}_{2}$ or $\mathrm{CO}_{2}$ evolution by $\mathrm{G}$ without any added $\mathrm{Ni}$, indicating that, at the higher concentrations than possibly found in $\mathrm{G}$, the activity of hydrogenation catalysts like $\mathrm{Ni}$ is negligible.

Besides metal impurities, another point of concern in catalysis is the possibility to reuse the same catalyst sample in consecutive runs. In the present case it was observed that both the activity for $\mathrm{H}_{2}$ and $\mathrm{CO}_{2}$ evolution in APR of EG decreases significantly upon reuse (Figure S2), the observed gas evolution being similar in the third use to that of the control experiments in the absence of any $G$ catalyst. This indicates that $G$ undergoes a considerable deactivation under the reaction conditions, becoming completely deactivated in the third use. It has been reported that one of the most common reasons for $G$ deactivation is the loss $2 \mathrm{D}$ morphology with the formation of $3 \mathrm{D}$ objects that cannot disperse well in the reaction medium and sediment in the liquid phase. However, in the present case, TEM images of the deactivated catalyst still shows the expected sheet morphology for the inactive samples (Figure S3). Therefore, it is likely that deactivation of $G$ in the present case could be a consequence of the loss of the active sites. For hydrogenation reactions it has been proposed in literature that carbonyl groups and diketones at the periphery of the sheets as well as frustrated Lewis acid-base pairs are acting as the active sites ${ }^{[5 d, 14]}$. It could be that some species formed in the APR of EG, particularly carboxylic acids present in aqueous phase or even $\mathrm{H}_{2}$ gas deplete these active sites by reacting with them. Generated $\mathrm{H}_{2}$ at the reaction temperature can reduce $\mathrm{CO}$ groups or basic sites can be neutralised by carboxylic acids generated from EG in the process.

To provide some support to this proposal of $G$ deactivation, besides TEM, used $\mathrm{G}$ sample was also characterized by XPS, $T G, I R$ and Raman spectroscopy and the data compared to those of the fresh material. IR spectra of the $G$ sample, before and after being used as catalyst, were compared (see Figure S4). This spectra reveal the appearance in the used catalyst of sharp new bands appearing at 1385 and $1320 \mathrm{~cm}^{-1}$ on top of a broad background, due to $\mathrm{OH}$ stretching vibration at $3420 \mathrm{~cm}^{-1}$ and $\mathrm{C}=\mathrm{C}$ bonds at $1580 \mathrm{~cm}^{-1}$ characteristic of $\mathrm{G}$. It is proposed that these two new sharp peaks indicate the presence of the absorbed organic molecules $\left(\mathrm{CH}_{3}\right.$ and $\mathrm{CH}_{2}$ groups). In addition, significant changes in the XPS C1s peak between the fresh and used $G$, corresponding to a significant decrease in the proportion of graphenic $C$ atoms accompanied by an increase of the $\mathrm{C}$ atoms bounded to oxygen was observed (see Figure S5). No significant changes were observed in C Is XPS peak and the Raman spectra of the fresh and used samples, indicating that if some hydrogenation of active sites occurs it should be minor and not easily detectable by these two spectroscopies. In the case of TG, a somewhat higher weight loss at temperatures between 200-300 $\circ \mathrm{C}$ was observed for the used $\mathrm{G}$ catalyst indicating that the used $G$ sample should contain strongly adsorbed additional materials, probably masking or poisoning the actives sites. This being compatible with the observation of new vibration bands in IR. In contrast, no large variation between the fresh and used sample was recorded in Raman spectroscopy. Figures S4, S5, S6 and S7 in the supporting information present characterization data of the three times used deactivated $\mathrm{G}$ catalyst.

In a further experiment to understand deactivation, $G$ as a powder was previously treated in a flow reactor with a $\mathrm{H}_{2}$ stream at $300{ }^{\circ} \mathrm{C}$ for $3 \mathrm{~h}$ and then, the $\mathrm{H}_{2}$-treated $\mathrm{G}$ sample was used as catalyst for APR. The results observed indicate significant deactivation of the $G$ catalyst due to this pre-treatment. Figure S8 in the supporting information shows the temporal $\mathrm{H}_{2}$ evolution with pre-treated $\mathrm{G}$ that is almost coincident with that obtained in the absence of any catalyst.

To address the reaction mechanism, analysis of the aqueous phase was also performed after prolonged reaction, whereby a less than $10 \%$ of the initial EG amount was observed (see Table 1). Of the products reported in the literature as formed in the APR of EG in presence of metal-containing catalysts, we were able to detect the presence of methanol, ethanol and acetic acid, suggesting that $G$ as catalyst is following similar reaction pathways.

In this regard it is proposed that the APR of EG has to combine dehydrogenation steps leading to carbonylic compounds and carboxylates, as well as C-C bond breaking steps. In view of this, a plausible reaction mechanism could be consecutive dehydrogenation of EG leading to glyoxal and oxalic acid, followed by decarboxylation as indicated in Scheme 2.

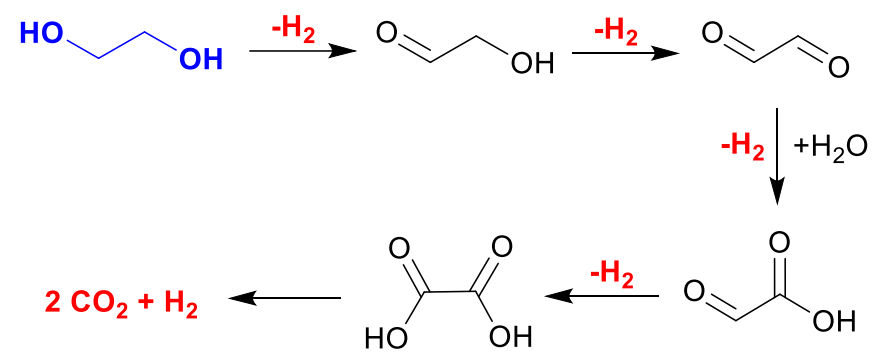

Scheme 2. Mechanistic proposal for the APR reaction of $E G$, involving dehydrogenation and C-C bond cleavage of oxalic acid. 
To gain some information about the feasibility of this mechanistic proposal, the reaction of oxalic acid under the reaction conditions in the absence of any catalyst was performed, whereby a complete spontaneous, uncatalysed decomposition of oxalic acid to $\mathrm{CO}_{2}$ and $\mathrm{H}_{2}$ was observed (see Figure 3). This thermal decomposition of oxalic acid is well known in literature ${ }^{[15]}$ and attributed to the easy of C-C bond cleavage when two carbonyl groups are neighbours as consequence of the Coulombic repulsion of the two carbons bearing partial positive charge. In contrast to the complete decomposition of oxalic acid, another control reaction under the same conditions shows that glyoxal only undergoes a partial decomposition to $\mathrm{H}_{2}$ and $\mathrm{CO}_{2}$ in the absence of catalyst reaching $31 \% \mathrm{~mol} \mathrm{H}_{2}$ respect to the maximum theoretical value (300 \% mol $\mathrm{H2} / \mathrm{mol}$ glyoxal) (Figure 3). Moreover, to further support the dehydrogenation ability of $\mathrm{G}$, glyoxal as substrate was also submitted to the APR conditions using $\mathrm{G}$ as catalyst, whereby an increase in the formation of $\mathrm{H}_{2}$ and $\mathrm{CO}_{2}$ respect to the uncatalyzed process was observed (Figure S9). This activity data indicates that if glyoxal were one of the reaction intermediates, spontaneous and catalyzed decomposition would occur leading to $\mathrm{H}_{2}$ and $\mathrm{CO}_{2}$. It should, though, be noted that the proportion of $\mathrm{CO}_{2}$ is higher than expected according to the ideal APR mechanism indicated in scheme 2.

Based on these control data it is suggested that the role of $G$ as catalyst is mainly to promote the dehydrogenation of $E G$ and other intermediates forming aldehydes and carboxylic acids that spontaneously will decarboxylate under the reaction conditions. Since $G$ has been found to promote hydrogenation of $C-C$ double and triple bonds as well as nitro groups ${ }^{[5 \mathrm{~d}, 5 \mathrm{e}]}$, this material should also exhibit activity for the reverse process, dehydrogenations, on the same type of active sites. Although the nature of active sites is still unclear, proposals have been made based on the catalytic activity of organic molecules as hydrogenation organocatalyst. In this organocatalytic activation of $\mathrm{H}_{2}$, hydrogenation occurs due to the combined action of Lewis acid and base pairs in a rigid molecule at distances close enough to interact with $\mathrm{H}_{2}$ molecule, but not so close to collapse by mutual neutralization. Such structures have been denoted as "frustrated Lewis acid-base pairs" and have also been proposed to be present on $\mathrm{G}^{[\mathrm{[d}]}$. In fact, precedents in the literature have shown that $\mathrm{G}$ exhibits also activity for dehydrogenation of $\mathrm{C}-\mathrm{C}$ multiple bonds by $\mathrm{H}_{2}$ and frustrated Lewis acid-base pairs were also claimed as the active sites responsible for this hydrogenation activity ${ }^{[5 d]}$. If this is the case, generation of acids or bases during the reaction should interfere on the catalytic activity by neutralization of the sites with appropriate nature as it has been observed in other cases $^{[5 d]}$.
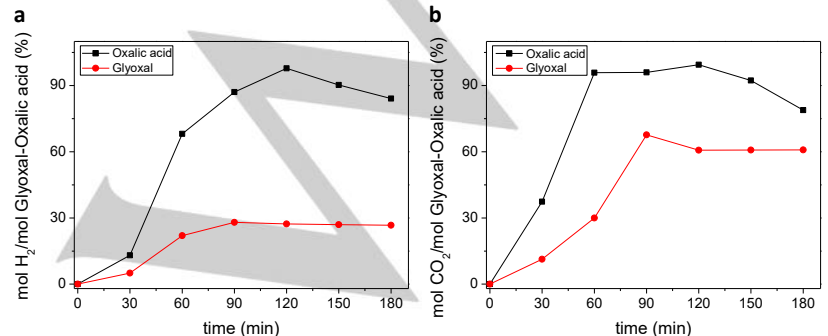

Figure 3. Temporal evolution of $\mathrm{H}_{2}(\mathrm{a})$ and $\mathrm{CO}_{2}$ (b) during the hydrothermal treatment of oxalic acid and glyoxal in the absence of any $\mathrm{G}$ catalyst. Reaction conditions: $250^{\circ} \mathrm{C}, 1 \mathrm{~atm}$, substrate $4.48 \mathrm{mmol}$, no catalyst.

In order to provide additional support for this mechanistic proposal, some quenching experiments were carried out using carbon-centred and oxygen radical quenchers. Specifically DMSO was used as selective hydroxyl radical $(\cdot \mathrm{OH})$ quencher and benzophenone as selective hydroperoxyl radical $(\cdot \mathrm{OOH})$ quencher. No influence of the presence of these quenchers in the reaction media was observed and the temporal profiles of the reactions in the presence of these two potential quenchers were coincident within the experimental error with that of the reaction carried out in the absence of quencher (Figure 4). In contrast, when the reaction was carried out using ascorbic acid as carbon-centred radical trapping agent in water, a certain decrease in the amount of $\mathrm{H}_{2}$ evolution was observed. These quenching studies indicate that reactive oxygen species that derive from $\mathrm{H}_{2} \mathrm{O}$ are not responsible for the APR process, although some of the pathways may, however, involve some minor contribution of $C$ centred radicals in accordance with the influence of the presence of ascorbic acid.

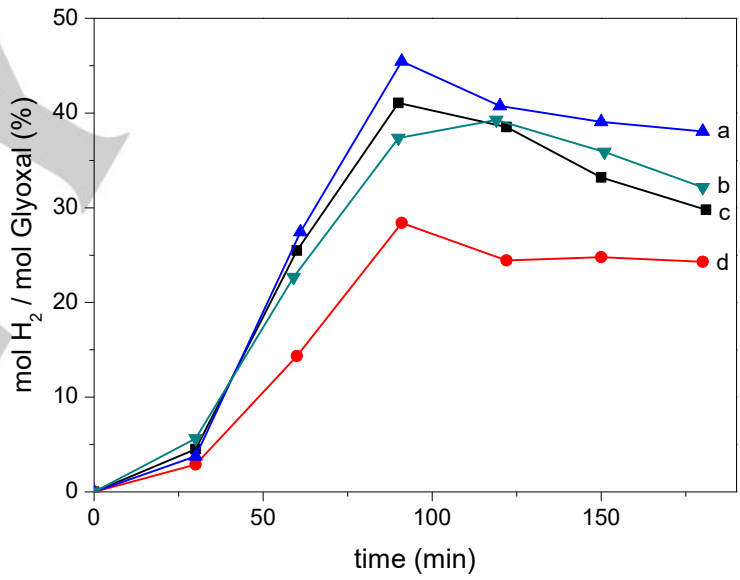

Figure 4. Temporal profiles for $\mathrm{H}_{2}$ evolution of the APR reaction of glyoxal catalysed by $\mathrm{G}$ in the presence of radical quenchers a) Benzoquinone b) $\mathrm{G}$ c) DMSO d) Ascorbic Acid. Reaction conditions: $250 \stackrel{\circ}{\circ}$, 1 atm, $4.48 \mathrm{mmol}$ glyoxal, $110 \mathrm{mg} \mathrm{G}$ catalyst, amount of quencher $0.4 \mathrm{mmol}$.

The reaction most likely involves some reaction intermediates with C. radical character.

In summary, in the present work evidence has been provided in support of the catalytic activity of graphenes as metal free catalysts for APR of EG. Among the samples tested the one obtained by alginate pyrolysis was the most active, although the material loses a significant activity upon reuse. Addition of increasing amounts of $\mathrm{Ni}^{2+}$ as metal impurity indicates that the activity of $G$ is not due to impurities of this metal that could be present in the sample. It is proposed that the catalytic activity from $G$ derives from the hydrogenation/dehydrogenation sites present in these defectives Gs and that these sites decrease in number upon reuse of the material. 


\section{Acknowledgements}

Financial support by the Spanish Ministry of Economy and Competitiveness (Severo Ochoa and CTQ2012-32315) and Generalitat Valenciana (Prometeo 2013-019) is gratefully acknowledged. I.E.-A. thank to Spanish Ministry of Science for $\mathrm{PhD}$ scholarships. This research is partly funded by the EUJSPS joint initiative through the NOVACAM project.

Keywords: Heterogeneous catalysis • sustainable chemistry • carbocatalysis $\bullet$ graphene as metal-free catalyst $\bullet$ biomass reforming

[1] aA. Schaetz, M. Zeltner, W. J. Stark, ACS Catalysis 2012, 2, 1267 1284; bM.-M. Titirici, M. Antonietti, Chem. Soc. Rev. 2010, 39, 103-116.

[2] aS. Navalon, A. Dhakshinamoorthy, M. Alvaro, H. Garcia, Chem. Rev. 2014, 114, 6179-6212; bJ. Pyun, Angew. Chem. Int. Ed. 2011, 50, 4648; cC. Su, K. P. Loh, Acc. Chem. Res. 2013, 46, 2275-2285.

[3] aA. K. Geim, Science 2009, 324, 1530-1534; bK. S. Novoselov, A. K. Geim, S. V. Morozov, D. Jiang, Y. Zhang, S. V. Dubonos, I. V. Grigorieva, A. A. Firsov, Science 2004, 306, 666-669.

[4] J. Albero, H. Garcia, J. Mol. Catal. A 2015, 408, 296-309.

[5] aA. Dhakshinamoorthy, A. Primo, P. Concepcion, M. Alvaro, H. Garcia, Chem. Eur. J. 2013, 19, 7547-7554; bD. R. Dreyer, H.-P. Jia, C. W. Bielawski, Angew. Chem. Int. Ed. 2010, 49, 6813-6816; cD. R. Dreyer, H.-P. Jia, A. D. Todd, J. Geng, C. W. Bielawski, Org. Biomol. Chem. 2011, 9, 7292-7295; dA. Primo, F. Neatu, M. Florea, V. Parvulescu, H. Garcia, Nat. Commun. 2014, 5, 5291; eM.-M. Trandafir, M. Florea, F.
Neaţu, A. Primo, V. I. Parvulescu, H. García, ChemSusChem 2016, 9, 1565-1569.

[6] R. D. Cortright, R. R. Davda, J. A. Dumesic, Nature 2002, 418, 964-967.

[7] aG. W. Huber, J. W. Shabaker, S. T. Evans, J. A. Dumesic, Appl. Catal., B 2006, 62, 226-235; bJ. W. Shabaker, G. W. Huber, R. R. Davda, R. D. Cortright, J. A. Dumesic, Catal. Lett. 2003, 88, 1-8.

[8] R. R. Davda, J. W. Shabaker, G. W. Huber, R. D. Cortright, J. A. Dumesic, Appl. Catal., B 2003, 43, 13-26.

[9] aD. M. Alonso, S. G. Wettstein, J. A. Dumesic, Chem. Soc. Rev. 2012, 41, 8075-8098; bA. Ciftci, D. A. J. M. Ligthart, E. J. M. Hensen, Green Chemistry 2014, 16, 853-863; cD. L. King, L. Zhang, G. Xia, A. M. Karim, D. J. Heldebrant, X. Wang, T. Peterson, Y. Wang, Appl. Catal., $B$ 2010, 99, 206-213; dY. Shinmi, S. Koso, T. Kubota, Y. Nakagawa, K. Tomishige, Appl. Catal., B 2010, 94, 318-326.

[10] A. Primo, A. Forneli, A. Corma, H. García, ChemSusChem 2012, 5, 2207-2214.

[11] W. S. Hummers, R. E. Offeman, J. Am. Chem. Soc. 1958, 80, 13391339.

[12] aW. Gao, L. B. Alemany, L. Ci, P. M. Ajayan, Nat Chem 2009, 1, 403408; bX. Mei, X. Meng, F. Wu, Physica E 2015, 68, 81-86.

[13] aA. Ambrosi, S. Y. Chee, B. Khezri, R. D. Webster, Z. Sofer, M. Pumera, Angew. Chem. Int. Ed. 2012, 51, 500-503; bA. Ambrosi, C. K Chua, B. Khezri, Z. Sofer, R. D. Webster, M. Pumera, Proc. Natl. Acad. Sci. 2012, 109, 12899-12904.

[14] aE. Despiau-Pujo, A. Davydova, G. Cunge, L. Delfour, L. Magaud, D. B. Graves, J. Appl. Phys. 2013, 113, 114302; bL. J. Hounjet, D. W Stephan, Org. Process Res. Dev. 2014, 18, 385-391; cD. W. Stephan, Org. Biomol. Chem. 2008, 6, 1535-1539; dD. W. Stephan, G. Erker, Angew. Chem. Int. Ed. 2010, 49, 46-76.

[15] aL. J. Crossey, Geochim. Cosmochim. Acta 1991, 55, 1515-1527; bJ. Higgins, X. Zhou, R. Liu, T. T. S. Huang, J. Phys. Chem. A 1997, 101 2702-2708. 
Entry for the Table of Contents (Please choose one layout)

\section{COMMUNICATION}

Graphene in the absence of any metal catalyzes the decompositio of ethylene glycol into hydrogen and carbon dioxide in hydrogenating/dehydrogenating sites но

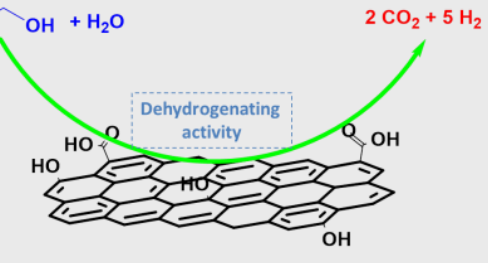

Iván Esteve-Adella, Nadia Bakker ${ }^{a, b}$, Ana Primo ${ }^{a}$, Emiel J.M. Hensen ${ }^{b}$,

Hermenegildo García *

Page No. - Page No.

Graphene as metal free catalyst for aqueous phase reforming of ethylene glycol 